\section{Pine Tree Tapping in Siberia with Special Reference to Alco- hol Consumption}

Keywords: Alcoholism; Toxicity; Public health; Forestry works

\section{Introduction}

Previously we have reported on toxic admixtures to alcoholic beverages legally sold in Russia [1,2]. During the anti-alcohol campaign in the former Soviet Union (SU) (1985-1988), many distilleries producing alcoholic beverages of standard quality were closed and dismantled. Restrictions of sales resulted in drinking by many people of industrial liquids, window cleaner, lotions etc. Considering the large scale of the window cleaner sales in some places e.g. in Siberia, it was knowingly tolerated by authorities. The alcohol consumption predictably increased after the campaign. At the same time, technical alcohol (synthetic and cellulosic) found no demand from the stagnating industry. Official permissions to use alcohol from non-edible raw materials for the production of beverages were issued during the 1990s. On the background of disrespect for some laws and regulations, diluted technical alcohol was sold in vodka bottles through legally operating shops and eateries, added to beer, wine and other beverages. Following the abolition of the state alcohol monopoly in 1992, the country was flooded by low-quality alcoholic beverages. Alcohol was imported also from other countries, in particular, from the former Soviet republics of Transcaucasia. The author observed a huge line of tank trucks with ethanol at a border crossing. It is unknown, whether and how those gasoline tankers had been cleaned. Unscrupulous manufacturers would neither spend much money on the washing of bottles and necessary equipment; the disdainful attitude of some new Russian business to the mass consumer is known. North Caucasus has been generally known as

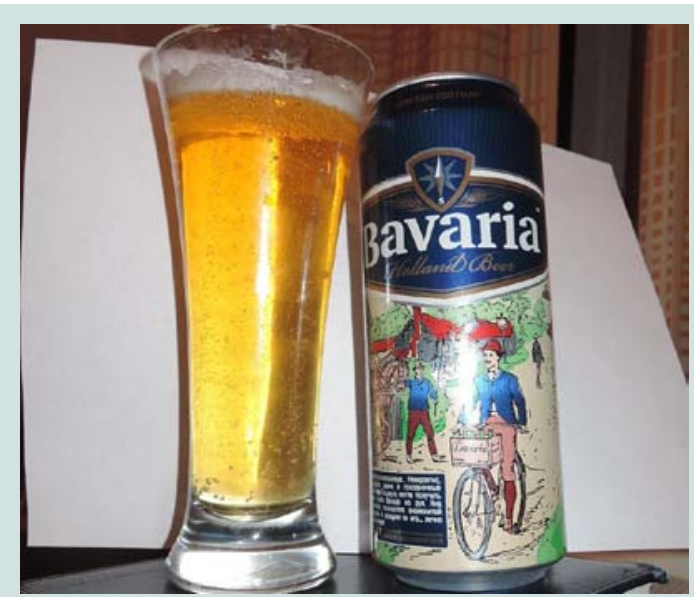

Figure 1: "Bavaria Holland Beer" made in Russia. Today the quality of alcoholic beverages is better than 10 years ago.

\section{Journal of}

\section{Addiction \& Prevention}

a nationwide source of cheap alcoholic beverages [3]. The quality of sold alcohol seems to have improved since approximately the last decade (Figure 1), although beer and other beverages do sometimes smell technical alcohol.

Some papers create an impression that consumers deliberately purchase surrogates for drinking [4,5]; discussed in [2]. According to our observations and generally known facts, drinking of technical liquids and lotions has decreased abruptly after the end of the antialcohol campaign in 1989, when vodka, beer and other beverages have become easily available and relatively cheap [6]. The only major exceptions are medicinal and technical alcohol purloined at some workplaces as well as alcohol-containing liquids from the pharmacy. Many alcohol-dependent people go to the pharmacy not because of the lower price but as they hope to obtain quality alcohol i.e. better purified than vodka from the bottle store. Converted to absolute alcohol, the tinctures from pharmacies are currently more expensive than the cheapest vodka. Recently it was reported on 77 dead from a mass poisoning in Irkutsk. According to the Russian sources summarized in Wikipedia $[7,8]$, the poisoning was caused by the bath lotion Boyaryshnik (Hawthorn) containing according to the label "93\% of ethyl alcohol, hawthorn extract, lemon oil, diethyl phthalate and glycerol", while the chemical analysis has reportedly shown that the lotion "contained methyl alcohol and antifreeze" [8]. There is a suspicion, however, that the poisoning was caused by the hawthorn (Crataegus) tincture from the pharmacy, containing $70 \%$ ethanol, prescribed by drops to patients with cardiac diseases (Figure 2) [9]. The hawthorn tincture is the most common form of medicinal alcohol drunk in Russia $[10,11]$. The author has not found any information neither on the hawthorn bath lotion nor generally on bath lotions containing 93\% ethanol. Apparently, there has been misinformation intended to disguise the fact that methanol (or another surrogate) was used for production of the hawthorn tincture as a cheaper substitute for medicinal alcohol. Moreover, mass poisonings with liver injury caused by disinfectant sold in vodka bottles, discussed in [2], could have been caused by admixture of "chloride compounds" [4] i.e. organochlorides. More details are in [2]. 


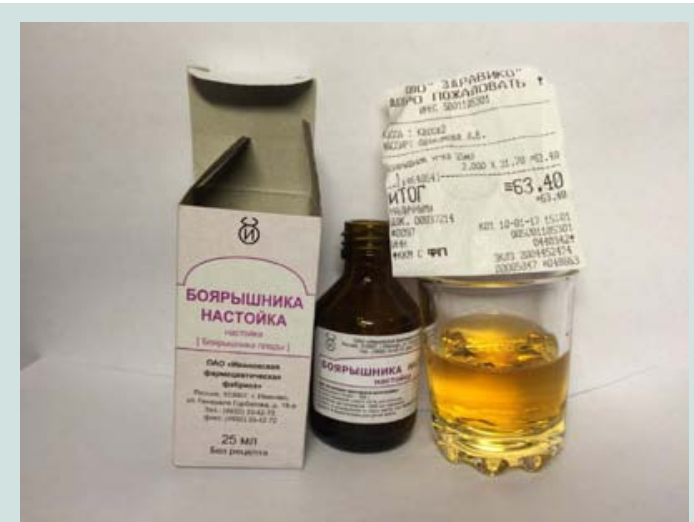

Figure 2: Hawthorn (Crataegus) tincture, containing $70 \%$ ethanol, is the pharmacy product most frequently drunk in Russia $[10,11]$. Some people buy it as they hope to obtain better quality alcohol than vodka from the shop. It is more expensive than cheapest vodka: $50 \mathrm{ml}$ (roughly equivalent to $90 \mathrm{ml}$ of vodka) costs about 1 US dollar.

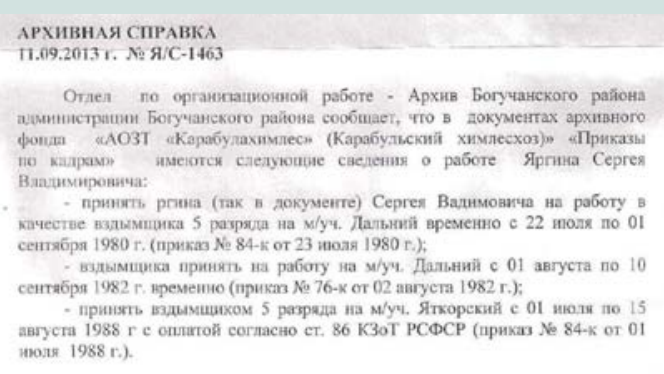

Figure 3 Certificate confirming works in pine tree tapping. The factual working time was longer than indicated on the certificate.

\section{Pine Tree Tapping in Siberia and Alcohol Consumption}

True incidence of poisonings is unknown; in the absence of reliable statistics, observations are important as they enable making practice-relevant conclusions. Here follow the author's observations during pine tree tapping works in Siberia. The topic of alcohol misuse is of importance for the forest works in Russia. Drunkenness is known to be associated with losses of working time, insufficient safety, low quality of working, and probably also forest fires due to negligence.

Pine tree tapping is aimed at oleoresin extraction, which is used to produce rosin and turpentine. Resin is obtained from the tree in a similar way as in rubber tapping, which involves the installation of the collection system, tree wounding to induce resin flow, and, except for certain methods, application of a chemical stimulant of the resin flow $[12,13]$. The tapping is a seasonal work: the summer season plus several weeks in winter and occasional works at other times. Inhabitants of the forest dwellings (cottages where e.g. 10-15 workers live) worked in the pine tree tapping; some of them hunted, gathered berries etc. To buy vodka, forest workers had to travel with timber trucks to the village. Some forest workers bought vodka. Besides, water/sugar mixture (wash) with added yeast (named 'braga') was fermented and consumed or distilled to samogon (moonshine). Certain workers did not drink alcohol and worked diligently, married, acquired houses etc. There was a gender imbalance among forest workers with prevalence of men. The ethnic origin was predominantly Russian. Many inhabitants had no documents; some of them were former prisoners having not found their way back to European Russia. Some people have become homeless as a result of property-related crime [14]. In Siberia, there have been many homeless people named Beaches. It is said that the word Beach has derived from English (hence the spelling); we do not know whether it is true or not. In Siberian cities such as Krasnoyarsk homeless people could be seen in the streets in winter.

The author (Sergei) worked in the pine tree tapping during the summer seasons 1980, 1982 and 1988 (Figure 3). In 1982 three workers came from Moscow; Sergei was chief as he was there for the second time; he informed the others that as long as there are no heavy rains they must work and abstain from drinking alcohol. Everybody agreed. There was also another reason for the abstinence: vodka in Siberia was generally low quality being produced from cellulosic alcohol $[3,15,16]$. The summer 1982 was favorable for the tapping; the weather was good. Sergei cut pine trees; two other workers from Moscow collected resin. They had not consumed alcohol until the August 21 $1^{\text {st }}$, which is the birthday of Sergei. He returned to the dwelling in the evening and saw two bottles of vodka and a pan with fried mushrooms on the table. It was a surprise from coworkers. There was a lot of work in those sunny days in August; and local workers did not drink at that time. The party organized by Muscovites provoked them; so the locals consumed alcohol this and the following day. Next day there was headache thanks to the poor quality of vodka. The Muscovites decided not to work and started heating the banya (Russian sauna) - a hut with a stove to produce wet heat for sweating; drinkers believe that it is good for detoxification. Some locals were also absent from work as their working rhythm was deranged by the party. The result of this derangement was not long in coming. An inebriated worker entered the banya, slipped on the wet floor and fell down onto the glowing iron stove, stood up and fell down again. He was dragged out of the banya. The burnt skin surface was extensive; there were not enough bandages. The worker was brought to the village and hospitalized. His further destiny is unknown; the post-burn scars could have impaired movements of his arms interfering with his future work. This was a sequel of the alcohol misuse during the working season. There is also a question of safety of primitive rural banyas that are often used by inebriated people. Next time they worked in Siberia in 1988 during the anti-alcohol campaign (1985-1988). Vodka was expensive; many local people consumed window cleaner, a mixture of ethanol and propanol. Considering the large scale of the window cleaner sales, it was knowingly tolerated by authorities. Unconscious people and puddles of vomit could be seen in the village dormitory, where workers coming from the forest stayed.

\section{Environmental Aspects of Pine Tree Tapping}

Caustic soda $(\mathrm{NaOH})$ was illicitly used as a resin flow stimulant, which lowered the viability of pine trees and quality of rosin [17]. Concentrated caustic solution was used to corrode the cut surface of the trees. We have found no reports on comparable use of $\mathrm{NaOH}$ outside the former SU; it was only mentioned that $\mathrm{NaOH}$ and $\mathrm{KOH}$ had been tested for that purpose [13]. $\mathrm{NaOH}$ was sold to workers by some foremen. According to the literature [12,13] and the author's observations, a larger area of the tree surface has been used for 
tapping in the former SU compared to other countries. Apparently, the forest perished more rapidly due to these practices; then it was cut for timber, rotted on stand or burned down. Forest fires have been not infrequent in Siberia. Travelling with the Trans-Siberian railroad, not so much forest can be seen today compared e.g. to the 1970s. As the use of $\mathrm{NaOH}$ has been illicit, no safety regulations have been implemented. Splashes of caustic solution can get into a worker's eyes in the process of tree cutting, which the author experienced several times. It was necessary to carry a flask with water to rinse the eyes in such cases; but not all workers would care to carry a flask. Alcohol misuse contributed to irresponsible behavior, disregard of instructions, and possibly also forest fires.

\section{Conclusion}

Homeless people in Russia and especially in Siberia, where winters are colder, must have easy access to free shelters and dormitories. They should be helped to obtain identity documents and decent accommodations. Abstinence must be encouraged; but aged alcohol-dependent people should have a possibility to spend time in warm public houses and then go home, under the condition of maintenance of the public order. Experience of other countries in the field of welfare and public assistance should be studied. Improvement of professional skills and remuneration of personnel in homeless shelters, homes for the aged and psychiatric hospitals is necessary, while human rights in such facilities must be observed [18]. Future studies should be aimed at the toxicity and quality control of alcoholic beverages as well as foodstuff reported to contain antibiotics and other admixtures [19]. Modern methods e.g. gas chromatography can detect admixtures [20]. Authorities must supervise the quality of sold alcoholic beverages using the modern methods, confiscate from shops products containing technical alcohol and other industrial liquids sold in vodka bottles or added to other beverages.

\section{References}

1. Jargin SV (2016) Alcohol and alcoholism in Russia: insider's observations and review of literature. J Addict Prevention 4: 6

2. Jargin SV (2016) Alcohol abuse and toxicity of alcoholic beverages in Russia: recent history. ARC J Addict 1: 21-29.

3. Nemtsov A (2009) Alcoholic history of Russia: contemporary period. Moscow
Russia.

4. Khaltourina D, Korotayev A (2016) Alcohol control policies and alcoholrelated mortality in Russia: reply to Razvodovsky and Nemtsov. Alcohol Alcohol 51: 628-629.

5. Khaltourina D, Korotayev A (2015) Effects of specific alcohol control policy measures on alcohol-related mortality in Russia from 1998 to 2013. Alcohol Alcohol 50: 588-601.

6. Jargin SV (2010) Letter from Russia: minimal price for vodka established in Russia from 1 January 2010. Alcohol Alcohol 45: 586-588.

7. 2016 Irkutsk mass methanol poisoning. Wikipedia.

8. (2016) 48 people die after drinking bath lotion with antifreeze in Siberia. RT News.

9. Hawthorn tincture instructions

10. Monakhova YB, Kuballa T, Leitz J, Lachenmeier DW (2011) Determination of diethyl phthalate and polyhexamethylene guanidine in surrogate alcohol from Russia. Int J Anal Chem 2011: 7.

11. Gil A, Polikina O, Koroleva N, McKee M, Tomkins S, et al. (2009) Availability and characteristics of nonbeverage alcohols sold in 17 Russian cities in 2007. Alcohol Clin Exp Res 33: 79-85.

12. Füller TN, de Lima JC, de Costa F, Rodrigues-Corrêa KC, Fett-Neto AG (2016) Stimulant paste preparation and bark streak tapping technique for pine oleoresin extraction. Methods Mol Biol 1405: 19-26.

13. Panda $\mathrm{H}$ (2008) Handbook on oleoresin and pine chemicals (Rosin, Terpene Derivatives, Tall Oil, Resin \& Dimer Acids). Asia Pacific Business Press, Delhi, pp. 608

14. Jargin SV (2015) Elder abuse, manipulation towards suicide, and homicide: borders can be vague. Int J Emerg Ment Health 17:706-708.

15. Nuzhnyi VP (1995) Toxicological characteristic of ethyl alcohol, alcoholic beverages and of admixtures to them. Voprosy Narkologii 3: 65-74.

16. Govorin NV, Sakharov AV (2012) Alcohol-related mortality. Tomsk: Ivan Fedorov.

17. Bogdanov PE (1988) Quality decrease of rosin after the processing of resin obtained using illicit stimulants. Lesokhimia i Podsochka 5: 9-10.

18. Jargin SV (2015) Gilyarovsky and Gannushkin psychiatric hospitals in Moscow. Hektoen Int J.

19. (2016) Again antibiotics in milk. Federal Service for Veterinary and Phytosanitary Surveillance (Rosselkhoznadzor), Kaluga Branch.

20. Wiśniewska P, Śliwińska M, Dymerski T, Wardencki W, Namieśnik J (2015) Application of gas chromatography to analysis of spirit-based alcoholic beverages. Crit Rev Anal Chem 45: 201-225. 